CAPSULE COMMENTARIES

\title{
Capsule Commentary on Butler et al., "Ethical concerns in the care of patients with advanced kidney disease: a national retrospective study, 2000-2011"
}

\author{
F. Amos Bailey, MD \\ University of Colorado Anschutz Medical Campus, Aurora, CO, USA. \\ J Gen Intern Med 35(4):1355 \\ DOI: $10.1007 / \mathrm{s} 11606-019-05546-\mathrm{x}$ \\ (1) Society of General Internal Medicine (This is a U.S. government work and \\ not under copyright protection in the U.S.; foreign copyright protection \\ may apply) 2020
}

$\mathrm{B}$ utler and colleagues' article is of interest for not only their findings but also their methodology. This is an example of a mash-up of Big Data and qualitative research that can inspire others as we all learn to use these tools. The authors wanted to better understand the ethical concerns in kidney disease on a population level. The study used VHA electronic medical records to identify 28,568 veterans with end-stage renal disease who sought care at the VHA from 2001 to 2009. Using the Lucene text-searching software, they could identify the word "ethics" in the chart of over 1000 veterans leading to a review and qualitative analysis. They found that patients with a higher comorbidity and with a greater conflict between patients, their surrogates, and clinicians about preferences for dialysis and other life-prolonging treatments were more likely to have ethical issues. ${ }^{1}$

In 2018, Kurella et al. demonstrated that dialysis was often delayed in VAH versus Medicare and that there was greater likelihood of death in the Medicare population suggesting the potential dangers with starting dialysis. ${ }^{2}$ This danger can lead providers to have moral distress and ethical conflict when recommendations for more conservative treatment are resisted by patient and family. Recently, O'Hare et al. reported that only $11 \%$ of people receiving dialysis thought their prognosis could be less than 5 years when data demonstrates that $60 \%$ of patients on dialysis who don't get a renal transplant die within 5 years. ${ }^{3}$

These kinds of mismatch in prognostic understanding and benefit and dangers of dialysis, particularly in those with complex illness, are a likely nidus for ethical conflict. An additional issue that must be considered and studied is that of implicit bias as a source of conflict when providers and patients and families have vastly different backgrounds. A start would be for all providers to read/listen to The 1619 Project of the New York Times and specifically Episode 4: How the Bad Blood Started (https://www.nytimes.com/2019/ 09/13/podcasts/1619-slavery-healthcare.html?rref=collection\%2Fcolumn\%2F1619-project\&action=click\&contentCollection=podcasts\&region $=$ stream \&module $=$ stream $\_$unit\&version $=$ latest $\&$ contentPlacement $=3 \&$ pgtype $=$ collection) which provides historical context to racial health disparities that contribute to worse health outcomes, distrust of the healthcare system and are exacerbated by both explicit and implicit biases.

Corresponding Author: F. Amos Bailey, MD; University of Colorado Anschutz Medical Campus, Aurora, CO, USA (e-mail: amos. bailey@cuanschutz.edu).

\section{Compliance with Ethical Standards:}

Conflict of Interest: The author declares that he does not have a conflict of interest.

\section{REFERENCES}

1. Butler CR, Vig EK, O'Hare AM, Liu CF, Hebert PL, Won SP. Ethical concerns in the care of patients with advanced kidney disease: a national retrospective study, 2000-2011. J Gen Intern Med. https://doi.org/10. 1007/s11606-019-05466-w.

2. Kurella Tamura M, Thomas IC, Montez-Rath ME, Kapphahn K, Desai M, Gale RC, Asch SM. Dialysis Initiation and Mortality Among Older Veterans With Kidney Failure Treated in Medicare vs the Department of Veterans Affairs. JAMA Intern Med. 2018;178(5):657-664

3. O'Hare AM, Kurella Tamura M, Lavallee DC, Vig EK, Taylor JS, Hall YN, Katz R, Curtis JR, Engelberg RA. Assessment of Self reported Prognostic Expectations of People Undergoing Dialysis: United States Renal Data System Study of Treatment Preferences (USTATE). JAMA Intern Med. 2019. https://doi.org/10.1001/jamainternmed.2019.2879.

Publisher's Note Springer Nature remains neutral with regard to jurisdictional claims in published maps and institutional affiliations. 